\title{
Flowering ground vegetation benefits wild pollinators and fruit set of almond within arid smallholder orchards
}

\author{
Olivia Norfolk*, Markus P. Eichhorn and Francis Gilbert
}

School of Life Sciences, University of Nottingham

*Corresponding author: olivia norfolk@hotmail.com, School of Life Sciences, University of Nottingham, University Park, Nottingham, UK, NG7 2RD

Running title: Orchard ground flora boost pollination

\section{Abstract}

1. Pollination studies tend to focus on the conventional agriculture associated with Europe and the USA, leaving a gap in our understanding of how pollination services are maintained in smallholder agricultural systems that dominate much of the developing world.

2. In South Sinai, Egypt, almond is cultivated as part of an arid agroforestry system in traditional orchard gardens that contain a mixture of fruit trees inter-planted with vegetables and herbs. This study investigated the relative contribution of honeybees and wild insects for pollination of almond trees and assessed how flowering ground vegetation influenced pollinator densities and fruit set.

3. Results showed that almond was highly dependent on insect pollination, with bagged flowers producing less than $8 \%$ of the fruit set of insect and hand pollinated flowers. Fruit set was correlated with wild pollinator visitation, but not with honeybee visitation. Furthermore, the presence of honeybee hives had no effect upon fruit set.

5. The abundance and species richness of flowering ground vegetation was positively related to pollinator abundance within the gardens and associated with enhanced fruit set. Over half of the flowering ground flora were minority crops grown alongside almond, suggesting that facilitation can occur between simultaneously flowering crops.

6. In these diverse orchard gardens, flowering minority crops benefited wild pollinators and increased fruit set in the primary orchard crop. If mutual facilitation occurs between other crop species, then the diverse cropping systems associated with smallholder farms are likely to enhance pollination services within traditional agricultural landscapes.

Keywords: agriculture, conservation, ecosystem service, Egypt, pollination, yield 


\section{Introduction}

Smallholder farming systems provide a major source of global food production, with an estimated two billion people depending on them for income and food security (Tscharntke et al., 2012; Steward et al., 2014). Their farmers are often particularly reliant on the nutritional returns associated with pollination-dependent crops such as nuts, fruit and vegetables (Steward et al., 2014), yet crop pollination studies tend to focus on the intensive farming systems associated with temperate regions, particularly those of Europe and the USA (Archer et al., 2014, Mayer et al., 2011). Smallholdings tend to support high levels of crop diversity and are frequently cited as examples of sustainable agroecosystems that can maintain biodiversity and ecosystem functioning (Kremen \& Miles, 2012; Kremen et al., 2012, Tschartnke et al., 2012), thus understanding the dynamics of crop pollination in lowintensity smallholder systems may provide novel insight that cannot be gleaned from conventional systems.

Almond, Dulcis prunus (Mill.) D.A.Webb is traditionally cultivated by smallholder farmers across the Middle East, but is also farmed on a large, intensive scale in California. Studies in California have established the value of wild insects for almond pollination, demonstrating that fruit set increases in orchards where wild pollinators are present as compared to those with honeybees alone (Brittain et al., 2013b, Klein et al., 2012). Wild pollinators can struggle to persist in intensive Californian systems where floral resources are limited to the short flowering-period of the crop, but their numbers can be maintained in orchards located in landscapes with sufficient semi-natural habitat (Klein et al., 2012). In temperate systems, the proportion of semi-natural habitat in the landscape positively correlates with wild pollinator visitation rates and subsequent fruit set of both almond and cherry (Klein et al., 2012; Holzschuh et al., 2012), but this relationship was not detected in Israeli almond orchards (Pisanty \& Mandelik, 2015) suggesting that trends may differ in arid regions where water availability can put limits on the abundance of wild flowers in the natural habitat.

Local pollinator densities can also be enhanced through the introduction of flowering vegetation strips in Californian almond orchards (Klein et al., 2012) and similarly, flowering ground vegetation has been linked to an increase in pollinator densities and richness in cherry and apple orchards, though not to enhanced fruit set (Holzschuh et al., 2012; Rosa García \& Miñarro, 2014). Since smallholder 
orchards typically contain a high variety of cultivated and wild plants growing alongside trees, they provide an ideal system in which to study whether facilitative pollination can occur between flowering ground vegetation and orchard crops.

This study investigates the factors influencing almond pollination in low-intensity orchard gardens in South Sinai, Egypt. Unlike the conventional almond orchards of California, honeybees are not traditionally managed for pollination within these orchards, though they have been introduced to some sites in recent years $(<15 \mathrm{yr})$ for the economic gains associated with honey production. The orchard trees are under-planted with a variety of flowering minority crops which are utilised by a diverse community of wild pollinators and pollinator species richness has been directly linked to the abundance of ground vegetation within the orchards (Norfolk et al., 2014). This study evaluates the relative contribution of wild pollinators and honeybees for almond pollination and assesses whether the presence of flowering ground vegetation can reduce pollination deficits within this arid small-scale farming system.

\section{Methods}

Study Site

The study was conducted in the region around the town of St Katherine, South Sinai, Egypt $\left(28^{\circ} 33^{\prime} 20^{\prime \prime} \mathrm{N}, 33^{\circ} 58^{\prime} 34^{\prime \prime} \mathrm{E}\right)$, a mountainous region with elevations of 1350-2624 $\mathrm{m}$. The landscape is characterized by rugged mountains interspersed with steep-sided valleys (wadis). Along the bottom of these wadis run riverbeds that remain dry for most of the year, only temporarily returning to river beds during intermittent floods. The region has a hyper-arid climate, with dry, hot summers and cold winters. Average annual rainfall ranges from $10 \mathrm{~mm}$ per year in low coastal areas to $50 \mathrm{~mm}$ per year in the high mountains, but this entire annual rainfall can fall within the space of a single day as unpredictable flash floods (Cools et al., 2012). Traditionally the farms of local Bedouin are walled orchard gardens along the base of these wadis which depend on runoff rainwater for irrigation.

Gardens are farmed in an agroforestry style and typically contain a variety of orchard produce (almond, apple, pear, apricot, fig, olive, pomegranate), inter-planted with vegetables and herbs for domestic use. Gardeners generally weed the immediate vicinity of fruit trees, but wild plants are 
tolerated and frequently occur at higher numbers than they do in the surrounding habitat (Norfolk et al., 2013). The orchards are wholly organic; no pesticides or herbicides are used on the trees and goat manure is the only fertiliser. Orchard products are not produced commercially but primarily for subsistence or local sale.

Almond is the most abundant orchard crop, grown in $96 \%$ of all orchards with an average of 20 trees per orchard (Zalat et al., 2001). Almond trees tend to be planted in rows with an average spacing of 8 $\mathrm{m}( \pm 0.94)$ between individual trees, though some orchards contain single, isolated trees. The average size of the orchards is $2000 \mathrm{~m}^{2}$, with areas ranging from $500 \mathrm{~m}^{2}$ to $>6000 \mathrm{~m}^{2}$. Almond is the first fruit tree to flower in the region, allowing us to study the impact of ground flora on almond pollination without any confounding competition from other flowering orchard crops.

Domesticated honeybees have only been kept in St Katherine in recent years (Semida \& ElBanna, 2006) and though hives are now common close to the towns of St Katherine and Abu Seylah, they remain absent in the high mountains. Thirty trees were selected at random from three wadis within the vicinity of St Katherine, two which contained managed honeybee hives- ten were within the town gardens of St Katherine ( 1500 m.; hives present), ten within the low mountains gardens of Wadi Itlah ( $\sim 1350 \mathrm{~m}$; hives present) and ten from the high mountain gardens of Wadi Gebel (1800 m; hives absent). Sampled trees were a minimum of $50 \mathrm{~m}$ from one another and were selected at random from the total pool of trees present in each wadi. They were spread across 20 orchards, with an average of 1.5 sample trees per orchard ( $\max 3$ trees per orchard).

Pollination treatments

Each tree was subjected to three pollination treatments in order to determine the relative impact of wind, insect and optimal pollination on the fruit set: (1) bagged flowers (wind pollination only), (2) open flowers (wind and insect pollination), (3) hand-pollinated open flowers ('optimum' pollination). Treatments were randomly assigned to each of three branches per tree, giving a total of 30 replicates per treatment. For the 'bagged flowers' treatment branches were covered with polyethylene tulle bags for the whole duration of flowering. Bags prevented access to pollinating insects, but allowed windmediated pollen grains to pass through. Bags were removed after petal abscission to avoid shading the developing leaves and fruits. For the 'open' treatment, branches were marked and left freely exposed to all insect pollinators. For the 'hand pollinated' treatment, flowers were freely exposed to 
insect pollinators and were additionally hand-pollinated with the pollen of three flowers from a neighbouring tree to test for pollen limitation. In July, before birds and small mammals started feeding on the developed fruits, the number of developed fruits was counted on the same branches and was used to calculate fruit set. Extremely small and deformed fruits were noted and excluded from analysis.

Pollinator visitation to almond

Flower-visiting pollinators (honeybees, wild bees, hoverflies and beetles) were recorded from the $10^{\text {th }}$ February to $22^{\text {nd }}$ February 2014 during the flowering period of the almond trees, with surveys beginning directly after bud opening. Two 10-min observation rounds (AM and PM) were carried out for each of the thirty experimental trees. All morning observations conducted between 10:00-12:30 and afternoon observations between 12:30-15:00. Surveys were only conducted when conditions were suitable for pollinator activity (temperature $>18^{\circ} \mathrm{C}$, sunny weather, low wind). During the flowering period there were heavy rains and snow, which put surveying on hold for four days. Due to the small size of the trees and the relatively low numbers of flower-visitors it was possible to record all visitors by walking slowly around the tree. Pollinators were primarily identified in the field with voucher specimens collected for identification in the lab. Voucher specimens are deposited at the University of Nottingham. For calculation of visitation rates, the number of pollinators per tree was divided by the number of flowers in that tree. Visitation rates were summed across the two rounds.

The floral abundance and species richness of all flowering ground vegetation were recorded within a $10 \mathrm{~m} \times 10 \mathrm{~m}$ quadrat centred at each focal tree. Pollinators utilising the ground flora were recorded within the quadrat in both the AM and PM survey sessions, with a single observer walking at a steady pace around the quadrat, examining each flower and recording the abundance of all flower-visiting insects. Pollinator abundance was averaged across the two rounds. For each tree the distance to the nearest neighbouring almond tree and the number of flowers on conspecific trees within the quadrat were recorded.

The proportion of semi-natural habitat within the landscape was mapped using satellite imaging on Goggle Earth Pro version 7.0.3 within a circle of $1 \mathrm{~km}$ radius, centred on each of the surveyed trees. A $1 \mathrm{~km}$ radius was selected because solitary bees are known to be influenced by landscape factors at 
a relatively small scale, typically less than $1 \mathrm{~km}$ (Gathmann \& Tscharntke 2002; Steffan-Dewenter et al., 2002).

\section{Statistical analyses}

All statistical analyses were performed with R.3.0.2 software (R Team, 2013), with linear mixed-effect models using the Ime4 package (Bolker et al., 2009). The fruit set resulting from the three pollination treatments was analysed with pollination treatment as a predictor and tree, garden and wadi as random factors (nesting trees within garden within wadi). A post-hoc Tukey's HSD test was used to compare the three treatments.

The fruit set data were highly zero-inflated, but there was no evidence for pollen limitation being responsible for these low levels of fruit set; the high proportion of zeroes may have be a result of flowers failing to form fruit because of the extreme environmental conditions (snow and wind) experienced during the surveying period. To account for this, an arcsine transformation was applied to normalise the zero-inflated dataset (Ives, 2015) and then a separate models was performed on a truncated dataset, which excluded the non-zero values. Both the arcsine and truncated data were analysed using linear mixed-effect models, with initial models including an interaction between wild pollinator visitation and honeybee visitation, distance to nearest conspecific tree, conspecific floral abundance, the floral abundance and species richness of ground vegetation and the proportion of semi-natural habitat in the landscape. Models included garden nested within wadi as random factors. Model fit was assessed using AIC (Zuur et al., 2009) and the best fitting model included wild pollinator visitation, floral abundance and species richness of ground flora (Details of the model selection process are included in Appendix 1). The significance of fixed factors was tested by dropping these factors and comparing models with a likelihood ratio test (distributed as Chi-squared). $R^{2}$ values were obtained for linear mixed-effect models using the MuMln package (Barton 2014), with marginal $R^{2}$ GLMM values representing the variance explained by each fixed effect (Nakagawa \& Schielzeth, 2013). Wild pollinator and honeybee densities within the gardens were also analysed in linear mixed-effect models, with floral abundance and floral species richness as fixed effects and garden nested within wadi as random effects. Honeybee visitation, wild bee visitation and fruit set were then compared between the three wadis using linear mixed-effect models containing gardens as a random factor. 


\section{Results}

In total 364 flower-visiting pollinators were recorded during the sampling period, 243 visiting the almond trees and 120 visiting flowering ground vegetation within the gardens. Approximately threequarters of these flower-visitors were honeybees $(77 \%)$. Of the wild pollinators, half were wild bees (51\%; Apidae: Anthophora sp, Xylocopa sulcatipes, and Andrenidae: Andrena sp), 20\% were hoverflies (Syrphidae: Eupeodes corrollae, Eristalinus aeneus) and 23\% were Tropinota sp. beetles (Scarabidae: Cetoniinae). In total, 14 plant species were recorded in the ground floral beneath the trees (for full species list see Appendix 2); cultivated plants comprised $60 \%$ of the total floral abundance of ground vegetation and wild plants comprised $40 \%$.

Fruit set differed significantly between the three pollination treatments (Fig. 1, Imer. $x^{2}=13.3$, d.f. $=2, P$ $=0.001$ ) and was significantly lower for the bagged flowers which produced less than $8 \%$ of the fruits produced by open and hand pollinated flowers (Tukey post-hoc: open vs. hand: $P=0.920$, hand vs. bagged: $P=0.018$, open vs. bagged: $P=0.006$ ).

Fruit set was positively correlated with wild pollinator visitation rate (Table 1, Fig. 2A), but not with honeybee visitation rate (Fig. 2B). The abundance of wild pollinators and honeybees within the gardens was positively associated with the abundance and species richness of ground flora (Fig. $2 \mathrm{C}$ ). Fruit set was not affected by the distance to the next almond tree or the floral abundance of almonds within the vicinity (all $P>0.05$ ), but was enhanced by the abundance and species richness of ground flora found within the vicinity of the tree (Table 1, Fig. 2D). The proportion of semi-natural habitat in the landscape ranged from $70-90 \%$ and had no impact upon fruit set $(P>0.05)$.

Honeybee visitation rate differed significantly between trees located in the thee wadis $\left(I m e r: X^{2}=7.36\right.$, d.f. $=1, P=0.007$ ), and was considerably higher in St Katherine and Wadi Itlah where managed hives were present ( $27 \pm 4$ per 1000 flowers) than in Wadi Gebel where hives were absent ( $2 \pm 0.9)$. Wild pollinator visitation rates did not differ between the three wadis $\left(X^{2}=0.002\right.$, d.f. $\left.=1, P=0.962\right)$, nor did fruit set of the almond trees $\left(x^{2}=1.11\right.$, d.f. $\left.=1, P=0.290\right)$.

\section{Discussion}

The value of flowering ground vegetation 
The high diversity of wild and cultivated flora associated with these low-intensity orchards had a positive impact upon pollinator densities and subsequent fruit set of the almond crop. Flowering ground vegetation has been shown to enhance pollinator numbers in conventional orchards in Europe and the USA (Klein et al., 2012; Holzschuh et al., 2012; Rosa García \& Miñarro, 2014) and this study confirms that this positive association also holds true in arid smallholder systems. Previous studies of almond and cherry have not detected a positive relationship between ground vegetation and subsequent fruit set (Klein et al., 2012; Holzschuh et al., 2012), though facilitation effects have been observed in several other crop species such as mango, sunflower and blueberry where the presence of non-crop species attracted higher pollinator densities and increased yields (Carvalheiro et al., 2011; Carvalheiro et al., 2012, Blaauw \& Isaacs, 2014). The results of this study suggest that flowering ground vegetation within smallholder orchards can have a positive impact upon pollination services and that simultaneously flowering plants are not necessarily a threat to tree yields.

In conventional orchard systems in Europe and the USA, fruit set has been shown to increase with the proportion of semi-natural habitat in the surrounding landscape, but has not be affected by local levels of floral vegetation within orchards (Holzschuh et al., 2012; Klein et al., 2012). In this lowintensity system, orchards contain higher levels of floral resources than the expansive desert habitat (Norfolk et al., 2014) and though the proportion of natural habitat in the landscape was high, it had no impact upon pollinator densities or fruit set within orchards which were more strongly influenced by local factors. Setting aside semi-natural habitat may be a successful strategy for improving pollination services in temperate environments, but in arid regions where the natural habitat is relatively resource-poor more effective results might be achieved by enhancing on-farm floral abundance and diversity.

Over half of the ground flora within the orchard gardens were actively cultivated crops such as rocket, rosemary and strawberry, inter-planted amongst the trees. Studies of simple mixed-crop systems have shown that inter-cropping red pepper crops with basil can increase in bee abundance and richness, leading to an increase in the quality of the pepper crop (Pereira et al., 2015) and our results suggest that smallholder farming systems that maintain a diversity of co-flowering crop species may provide similar beneficial effects. If mutual facilitation can occur between other crop species, then 
diverse cropping systems may provide the opportunity to increase the effectiveness of pollination services in agricultural landscapes.

Pollination efficiency of wild pollinators versus honeybees

This study confirmed that almond was highly dependent on insect pollination, with bagged flowers producing less than $8 \%$ as many fruits as insect pollinated flowers. Honeybees were the most abundant visitor to almond, outnumbering wild pollinators three to one, yet fruit set was positively correlated with the visitation rate of wild pollinators alone. This result is consistent with trends observed in Californian almond systems, where wild bee visitation and diversity were positively correlated with fruit set, but honeybee visitation was not (Klein et al., 2012). Single-visit assessment of pollen transfer is necessary to fully establish how pollination efficiency differs between wild and honey bees and in other orchard systems wild pollinators have been found to provide higher quality pollen transfer through a variety of mechanisms. The solitary bee, Osmia cornuta has been shown to provide higher levels of pollen deposition per visit than honeybees to almond (Bosch \& Blas, 1994), apple (Vicens \& Bosch, 2000) and pear (Monzón et al., 2004). Contact with the stigma depends on the collecting behaviour of the insect and solitary bees often collect pollen and nectar simultaneously, providing higher levels of stigma contact than honeybees (Bosch \& Blas, 1994). Higher levels of pollen deposition are only useful if the pollen is being transferred from compatible cultivars and wild pollinators have also been observed to move between cultivars more frequently than honeybees; in almond orchards Osmia cornuta was more likely to move between tree rows than honeybees, which rarely move between rows on a single foraging trip (Bosch \& Blas, 1994).

Interactions between species can also impact upon the quality of pollination services. Honeybees have been shown to modify their foraging behaviour in the presence of wild bees (Greenleaf \& Kremen, 2006) and in Californian almond orchards honeybees moved between rows more frequently when they encountered wild bees, resulting in higher overall pollination effectiveness (Brittain et al., 2013b). Through this mechanism wild pollinators have the potential to indirectly increase fruit set by modifying the behaviour of honeybees. This study does not explicitly test for this type of synergistic effect, but if such effects were occurring one might have expected fruit set to increase in sites containing actively managed honeybees, which it did not. 
Bee keeping is a relatively new phenomenon in St Katherine $(<15 y r s)$ and though hives are now common in St Katherine and Wadi Itlah, they remain absent from Wadi Gebel where honeybee visitation rate showed a ten-fold reduction. Proximity to hives tends to be a strong determining factor of honeybee visitation (Woodcock et al., 2013) and seems a likely explanation for the strong differences in honeybee visitation observed between the sites in this study. However it must be noted that the absence of hives in the higher mountains of Wadi Gebel relates to the site's relative inaccessibility, thus is unavoidably confounded by altitude. The altitudinal gradient of orchards sampled in this study ranged from $1300-1800 \mathrm{~m}$ and whilst this may have some impact upon pollinator behaviour, honeybees have been known to establish mountain colonies at altitudes exceeding $2500 \mathrm{~m}$ (Hepburn et al., 1998) so should have the potential to forage in all orchards surveyed within this study. Wild pollinator visitation rate did not differ between sites, despite the altitudinal gradient, nor did fruit set, suggesting that the introduction of hives near the towns has not had a beneficial effect upon almond pollination in the region.

Studies of Spanish almond found that hand-pollinated flowers achieved fruit sets ranging between 10 and $38 \%$, with $40 \%$ considered the maximum achievable (Bosch \& Blas, 1994). In this study mean fruit set was just under ten per cent for open flowers which seems low. However it is difficult to directly compare the quality of pollination services between systems because interactive effects such as nutrient limitation or water deficiency can also limit the maximum achievable fruit set (Bommarco et al., 2013; Lundin et al., 2013, Klein et al., 2015). Fruit set may have been reduced by the extreme weather experienced during the flowering season rather than from a pollination deficit, though the single year design of the study makes this difficult to confirm. Cold weather and high winds are known to decrease honeybee activity (Brittain et al., 2013a) so pollination in our study may have been disrupted during the storms, but it was also noted that the heavy rain and snow-fall resulted in high losses of flowers regardless of whether they had been pollinated.

\section{Conclusions}

This study showed that wild pollinators provided a higher level of pollinator service to almond than honeybees in these traditional orchard gardens. The introduction of honeybee hives had no impact upon fruit set, which was positively associated with visitation rates from wild pollinators exclusively. The presence of additional flowering vegetation, both cultivated and wild, had a beneficial effect upon 
pollinator abundance within orchards and was associated with enhanced fruit set. These results suggest that pollination services to almond in the region cannot be maximised through the introduction of more honeybees, but that increasing the local abundance and diversity of ground flora within the orchard gardens could benefit wild pollinators and increase fruit set.

\section{Acknowledgements}

We would like to thank The Leverhulme Trust for funding; our local guide N. Mansour for his invaluable help and support in the field; the staff and manager M. Qotb at the St Katherine Protectorate for permissions and assistance; the Egyptian Environmental Affairs Agency for permission to work in the Park; H. Mubarak and all the staff at Fox Camp for providing facilities; and all of the orchard owners for their hospitality and permission to work on their land.

\section{References}

Archer, C. R., Pirk, C. W. W., Carvalheiro, L. G., \& Nicolson, S. W. (2014) Economic and ecological implications of geographic bias in pollinator ecology in the light of pollinator declines. Oikos, 123, 401-407.

Barton, K. (2014) MuMIn: Mult-model inference. R package version 1.10.0. http://CRAN.Rproject.org/package=MuMln. Accessed: 22/08/2014.

Blaauw, B. R. \& Isaacs, R. (2014) Flower plantings increase wild bee abundance and the pollination services provided to a pollination-dependent crop. Journal of Applied Ecology, 51, 890-898.

Bolker, B. M., Brooks, M. E., Clark, C. J., Geange, S. W., Poulsen, J. R., Stevens, M. H. H. \& White, J.-S. S. (2009) Generalized linear mixed models: a practical guide for ecology and evolution. Trends in Ecology \& Evolution, 24, 127-135.

Bommarco, R., Kleijn, D. \& Potts, S. G. (2013) Ecological intensification: harnessing ecosystem services for food security, Trends in Ecology and Evolution, 28, 230-238.

Bosch, J. \& Blas, M. (1994) Foraging Behaviour and Pollinating Efficiency of Osmia cornuta and Apis mellifera on Almond (Hymenoptera, Megachilidae and Apidae). Applied Entomology and Zoology, 29, 1-9.

Brittain, C., Kremen, C. \& Klein, A.-M. (2013a) Biodiversity buffers pollination from changes in environmental conditions. Global Change Biology, 19, 540-547. 
Brittain, C., Williams, N., Kremen, C. \& Klein, A.-M. (2013b) Synergistic effects of non-Apis bees and honeybees for pollination services. Proceedings of the Royal Society B: Biological Sciences, 280.

Carvalheiro, L. G., Veldtman, R., Shenkute, A. G., Tesfay, G. B., Pirk, C. W. W., Donaldson, J. S. \& Nicolson, S. W. (2011) Natural and within-farmland biodiversity enhances crop productivity. Ecology Letters, 14, 251-259.

Carvalheiro, L. G., Seymour, C. L., Nicolson, S. W. \& Veldtman, R. (2012) Creating patches of native flowers facilitates crop pollination in large agricultural fields: mango as a case study. Journal of Applied Ecology, 49, 1373-1383.

Cools, J., Vanderkimpen, P., El Afandi, G., Abdelkhalek, A., Fockedey, S., El Sammany, M., Abdallah, G., El Bihery, M., Bauwens, W. \& Huygens, M. (2012) An early warning system for flash floods in hyper-arid Egypt. Natural Hazards and Earth Systems Science, 12, 443-457.

Gathmann, A. \& Tscharntke, T. (2002) Foraging ranges of solitary bees. Journal of Animal Ecology, 71, 757-764.

Greenleaf, S. S. \& Kremen, C. (2006) Wild bees enhance honeybees' pollination of hybrid sunflower. Proceedings of the National Academy of Sciences, 103, 13890-13895.

Hepburn, H. R., Youthed, C., Illgner, P., Radloff, S. E., \& Brown, R. E. (1998) Production of aerodynamic power in mountain honeybees (Apis mellifera).Naturwissenschaften, 85, 389390.

Holzschuh, A., Dudenhöffer, J.-H. \&Tscharntke, T. (2012) Landscapes with wild bee habitats enhance pollination, fruit set and yield of sweet cherry. Biological Conservation, 153, 101-107.

Ives, A. R. (2015) For testing the significance of regression coefficients, go ahead and log-transform count data, 6, 828-835.

Klein, A.-M., Brittain, C., Hendrix, S. D., Thorp, R., Williams, N. \& Kremen, C. (2012) Wild pollination services to California almond rely on semi-natural habitat. Journal of Applied Ecology, 49, 723-732

Klein, A.M., Hendrix, S.D., Clough, Y., Scofield, A. \& Kremen, C. (2015) Interacting effects of pollination, water and nutrients on fruit tree performance. Plant Biology, 17, 201-8.

Kremen, C., Iles, A. \& Bacon, C. (2012) Diversified farming systems: an agroecological, systemsbased alternative to modern industrial agriculture. Ecology and Society, 17, 44. 
Kremen, C., \& Miles, A. (2012) Ecosystem services in biologically diversified versus conventional farming systems: benefits, externalities, and trade-offs. Ecology and Society, 17, 40.

Lundin, O., Smith, H. G., Rundlöf, M. \& Bommarco, R. (2013) When ecosystem services interact: crop pollination benefits depend on the level of pest control. Proceedings of the Royal Society of Biological Sciences, 280, 2012-2243.

Mayer, C., Adler, L., Armbruster, W. S., Dafni, A., Eardley, C., Huang, S. Q., Kevan, P. G., Ollerton, J., Packer, L., Ssymank, A., Stout, J. C. \& Potts, S. G. (2011). Pollination ecology in the 21st century: key questions for future research. Journal of Pollination Ecology, 3, 8-23.

Monzón, V. H., Bosch, J. \& Retana, J. (2004) Foraging behavior and pollinating effectiveness of Osmia cornuta (Hymenoptera: Megachilidae) and Apis mellifera (Hymenoptera: Apidae) on "Comice" pear. Apidologie, 35, 575-585.

Nakagawa, S. \& Schielzeth, H. (2013) . A general and simple method for obtaining $R^{2}$ from generalized linear mixed-effects models. Methods in Ecology and Evolution, 4, 133-142.

Norfolk, O., Eichhorn, M. P. \& Gilbert, F. (2013) Traditional agricultural gardens conserve wild plants and functional richness in arid South Sinai. Basic and Applied Ecology, 14, 659-669.

Norfolk, O., Eichhorn, M.P. \& Gilbert, F. (2014) Culturally valuable minority crops provide a succession of floral resources for flower visitors in traditional orchard gardens. Biodiversity and Conservation, 23, 3199-3217.

Pereira, A. L. C., Taques, T. C., Valim, J. O. S., Madureira, A. P. \& Campos, W. G. (2015) The management of bee communities by intercropping with flowering basil (Ocimum basilicum) enhances pollination and yield of bell pepper (Capsicum annuum). Journal of Insect Conservation, 19, 479-486.

Pisanty, G., \& Mandelik, Y. (2015) Profiling crop pollinators: life history traits predict habitat use and crop visitation by Mediterranean wild bees. Ecological Applications, 25, 742-752.

R Development Core Team (2013) R: A Language and Environment for Statistical Computing. R Foundation for Statistical Computing, Vienna, Austria. http://www.R-project.org/

Rosa García, R. \& Miñarro, M. (2014) Role of floral resources in the conservation of pollinator communities in cider-apple orchards. Agriculture, Ecosystems \& Environment, 183, 118-126.

Semida, F. \& El Banna, S. (2006) Impact of Introduced Honeybees on Native Bees at St. Katherine Protectorate, South Sinai, Egypt. International Journal of Agriculture and Biology, 8, 191-194. 
Steffan-Dewenter, I., Münzenberg, U., Bürger, C., Thies, C. \& Tscharntke, T. (2002) Scale-dependent effects of landscape context on three pollinator guilds. Ecology, 83, 1421-1432.

Tscharntke, T., Clough, Y., Wanger, T. C., Jackson, L., Motzke, I., Perfecto, I., Vandermeer, J. \& Whitbread, A. (2012). Global food security, biodiversity conservation and the future of agricultural intensification. Biological Conservation, 151, 53-59.

Vicens, N. \& Bosch, J. (2000) Pollinating efficacy of Osmia cornuta and Apis mellifera (Hymenoptera: Megachilidae, Apidae) on 'red Delicious' apple. Environmental Entomology, 29, 235-240.

Woodcock, B. A., Edwards, M., Redhead, J., Meek, W. R., Nuttall, P., Falk, S.,Nowakowski, M. \& Pywell, R. F. (2013) Crop flower visitation by honeybees, bumblebees and solitary bees: Behavioural differences and diversity responses to landscape. Agriculture, Ecosystems \& Environment, 171, 1-8.

Zalat, S., Semida, F., Gilbert, F., El Banna, S., Sayed, E., El-Alqamy \& Behnke, J. (2001) Spatial variation in the biodiversity of Bedouin gardens in the St.Katherine Protectorate. Egypt. Egyptian Journal of Biology 3, 147-155.

Zuur, A., leno, E. N., Walker, N., Savelieve, A. A. \& Smith, G. M. (2009) Mixed Effects Models and Extensions in Ecology with R, Springer. 
Table 1. Results from best-fitting linear mixed-effect models assessing the impact of pollinator and local effects on fruit set in almond, and the effect of floral abundance and species richness on pollinator abundance within the orchards. Models included garden nested within wadi as random factors. $X^{2}$ tests the difference between models after the associated fixed factor has been dropped and $R^{2}$ GLMM is represents the variance explained by the fixed factor. Fruit set was analysed using 1) an arcsine transformation of the zero-inflated dataset and 2) using a truncated dataset that only contained values greater than zero.

\begin{tabular}{|c|c|c|c|c|c|}
\hline Response variable & Fixed factor & & $X^{2}(d . f .=1)$ & $\boldsymbol{P}$ & $\mathbf{R}_{\text {GLMM }}^{2}$ \\
\hline \multirow[t]{6}{*}{ Fruit set } & \multirow[t]{2}{*}{ Wild pollinator visitation (+) } & arc sin transformed & 2.99 & 0.082 & 0.09 \\
\hline & & greater than zero & 4.25 & 0.039 & 0.21 \\
\hline & \multirow[t]{2}{*}{ Abundance of ground flora $(+)$} & arc sin transformed & 4.56 & 0.032 & 0.15 \\
\hline & & greater than zero & 3.54 & 0.059 & 0.18 \\
\hline & \multirow[t]{2}{*}{ Species richness of ground flora $(+)$} & arc sin transformed & 6.85 & 0.008 & 0.22 \\
\hline & & greater than zero & 5.40 & 0.020 & 0.26 \\
\hline \multirow[t]{2}{*}{ Wild pollinator orchard abundance } & Floral abundance (+) & & 27.99 & $<0.001$ & 0.37 \\
\hline & Floral richness (+) & & 19.98 & $<0.001$ & 0.44 \\
\hline \multirow[t]{2}{*}{ Honeybee orchard abundance } & Floral abundance (+) & & 44.93 & $<0.001$ & 0.69 \\
\hline & Floral richness (+) & & 16.21 & $<0.001$ & 0.12 \\
\hline
\end{tabular}


Fig.1. Mean fruit set ( \pm Standard error) for the pollination treatments: open (insect + wind), hand ('optimum') and bagged (wind only).

Fig.2. Effect of a) wild pollinator visitation and b) honeybee visitation on fruit set; c) the effect of ground flora species richness on c) wild pollinator density per $100 \mathrm{~m}^{2}$ within the orchards and d) fruit set. Visitation rates are the number of individuals per 1000 flowers summed across the two sampling rounds. Solid lines indicate significant linear mixed-effect models $(P<0.05)$, dashed lines non-significant models $(P>0.05)$. Fruit set graphs only represent trees with fruit set greater than zero. 
FIG 1

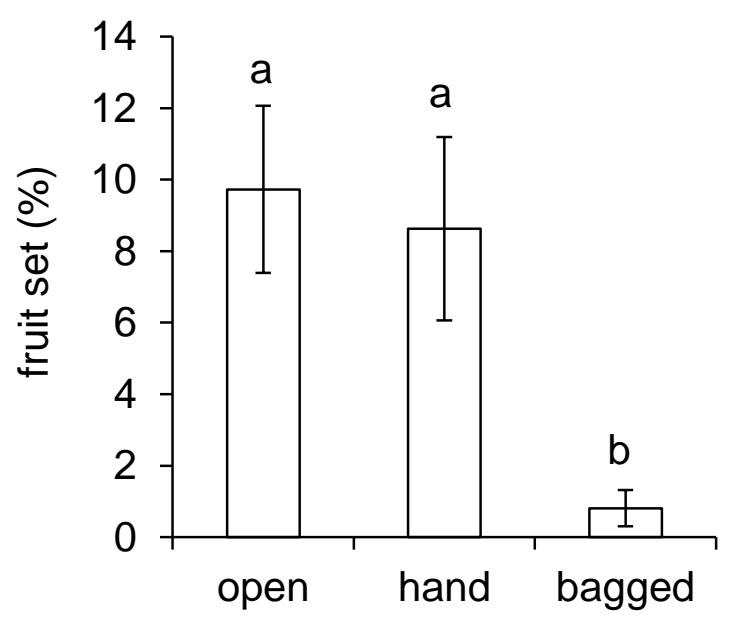


FIG 2

(a)

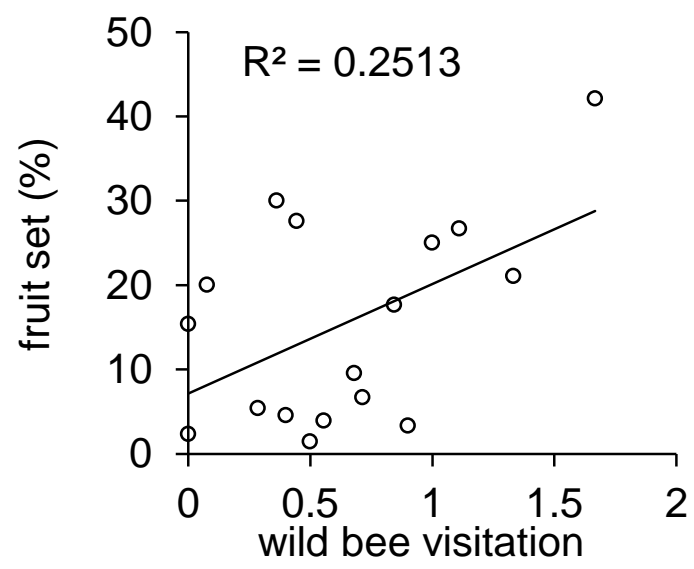

(c)

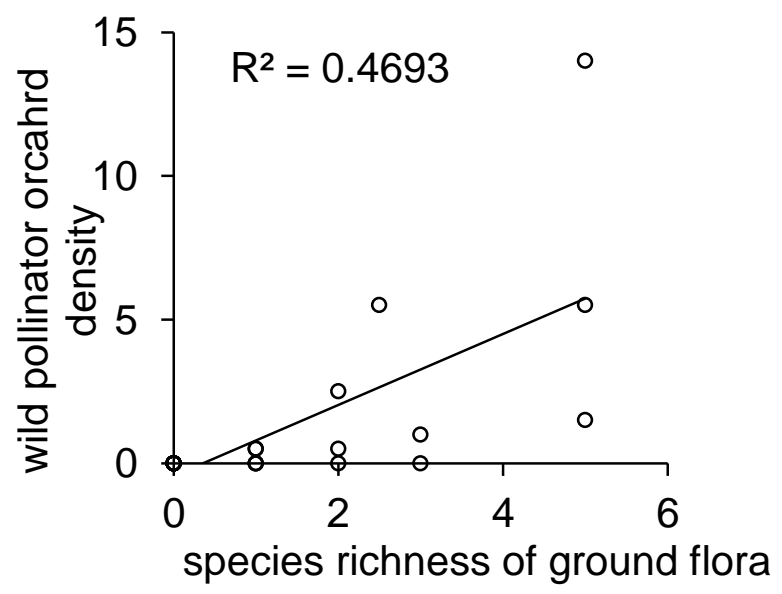

(b)

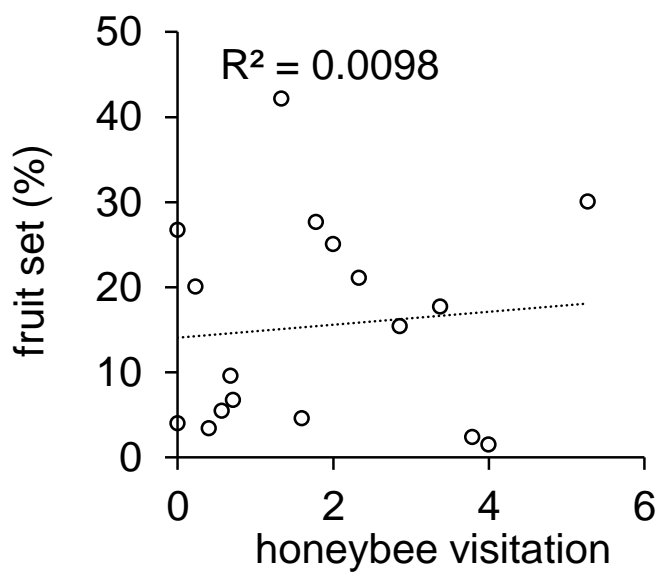

(d)

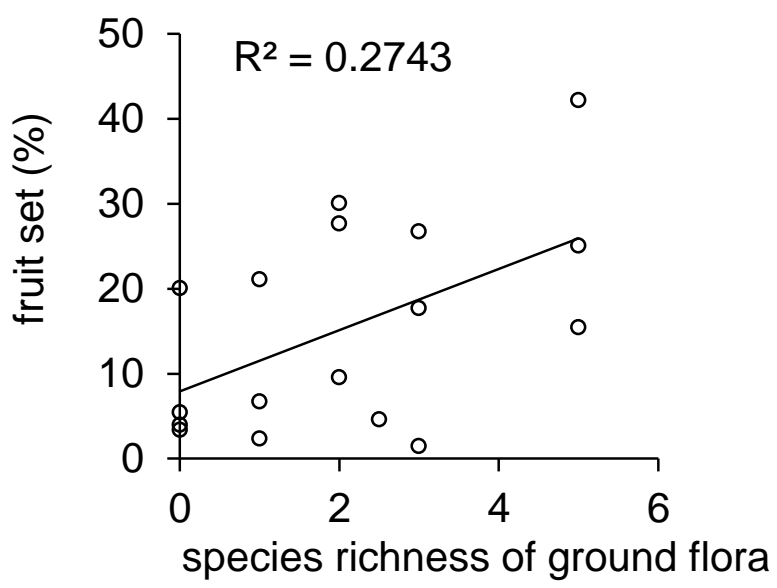


Appendix 1. Details of the model selection process for linear mixed effect models including fruit set (arc sin transformed and greater than zero), honeybee and wild pollinator orchard densities as response variables and garden nested within wadi as random effects. Best fitting models were selected according to AIC values (lowest AIC).

Fruit set (arc sin transformed)

Best model: Wild pollinator visitation + floral abun. + floral $s p$ richness

$\sim$ Honeybee visitation + floral abun. + floral sp richness

$\sim$ Wild pollinator ${ }^{*}$ Honeybee visitation +floral abun. + floral $\mathrm{sp}$ richness

$\sim$ Wild pollinator + Honeybee visitation +floral abundance + floral species richness+ distance to nearest tree

$\sim$ Wild pollinator + Honeybee visitation +floral abundance + floral species richness+ distance to nearest tree + conspecific floral abundance

$\sim$ Wild pollinator + Honeybee visitation +floral abundance + floral species richness+ distance to nearest tree + conspecific floral abundance + proportion semi-natural habitat

Fruit set (greater than zero)

Best model: $\sim$ Wild pollinator visitation + floral abun. + floral $s p$ richness

$\sim$ Honeybee visitation + floral abun. + floral sp richness

$\sim$ Wild pollinator * Honeybee visitation +floral abun. + floral $s p$ richness

$\sim$ Wild pollinator + Honeybee visitation +floral abundance + floral species richness+ distance to nearest tree

$\sim$ Wild pollinator + Honeybee visitation +floral abundance + floral species richness+ distance to nearest tree + conspecific floral abundance

$\sim$ Wild pollinator + Honeybee visitation +floral abundance + floral species richness + distance to nearest tree + conspecific floral abundance + proportion semi-natural habitat

\section{Honeybee orchard densities}

Best model: floral abundance + floral species richness

$\sim$ floral abundance

$\sim$ floral species richness

\section{Wild pollinator orchard densities}

Best model: floral abundance + floral species richness

$\sim$ floral abundance

$\sim$ floral species richness

AIC $\triangle$ AIC Log Lik df $R^{2}$

$\begin{array}{ccccc}-29.22 & 0 & 22.61 & 7 & 0.28 \\ -4.19 & 25.03 & 9.09 & 7 & 0.20 \\ -9.10 & 20.12 & 11.55 & 8 & 0.26 \\ 0.81 & 30.03 & 8.59 & 9 & 0.31 \\ 18.17 & 47.39 & 0.91 & & 0.32 \\ & & & 10 & \\ 19.20 & 48.42 & 0.82 & 11 & 0.33\end{array}$

\begin{tabular}{ccccc} 
AIC & $\Delta$ AIC & Log Lik & df & $R^{2}$ \\
\hline 114.89 & 0 & -49.44 & 7 & 0.25 \\
131.20 & 16.31 & -58.61 & 7 & 0.07 \\
125.93 & 11.04 & -55.96 & 8 & 0.24 \\
115.00 & 0.11 & -48.30 & 9 & 0.26 \\
121.05 & 6.61 & -50.76 & 10 & 0.27 \\
& & & & \\
122.26 & 7.37 & -50.13 & 11 & 0.29
\end{tabular}

\begin{tabular}{ccccc} 
AIC & $\Delta$ AIC & Log Lik & df & $R^{2}$ \\
\hline 132.04 & 0 & -61.02 & 5 & 0.82 \\
& & & & \\
146.64 & 14.6 & -69.32 & 4 & 0.67 \\
164.92 & 32.88 & -78.46 & 4 & 0.11 \\
& & & & \\
120.48 & 0 & -56.24 & 5 & 0.62 \\
& & & & \\
122.19 & 1.71 & -56.09 & 4 & 0.61 \\
121.26 & 0.78 & -56.63 & 4 & 0.44 \\
\hline
\end{tabular}


Appendix 2. Species list of the flowering ground vegetation recorded within the orchard gardens.

\begin{tabular}{lll}
\hline & \multicolumn{2}{c}{$\begin{array}{c}\text { abtal floral } \\
\text { abundance }\end{array}$} \\
\hline Cultivated & 60 \\
Rosmarinus officinalis L. & 44 \\
Eruca sativa Mill. & 15 \\
Mesembryanthemum sp & 0.5 \\
Fragaria vesca L. & 0.5 \\
Wild & 40 \\
Diplotaxis harra (Forssk.) Boiss. & 20 \\
Alkanna orientalis (L.) Boiss. & 8 \\
Arabidopsis kneuckeri (Bornm.) Schulz & 5 \\
Mosonia nivea Decne. ex Webb & 2 \\
Stachys aegyptiaca Pers. & 2 \\
Anchusa milleri Lam. ex Spreng. & 1.5 \\
Ochradenus baccatus Delile & 0.8 \\
Fagonia mollis Delile & 0.4 \\
Zilla spinosa (L.) Prantl & 0.3 \\
Launaea sp & 0.01 \\
\hline
\end{tabular}

